\title{
- dosmilveinte / veinteveinte -
}

\author{
Pablo Venegas Romero \\ Universidad de Valparaíso \\ pablo.venegas@uv.cl \\ Textos bajo licencia Creative Commons

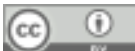 \\ Atribución 4.0 Internacional (CC BY 4.0)
}

Si el clima no se manifestase, el tiempo parecería romper con el paradigma de que avanza, por el contrario, más bien se asoma cercano a una idea mundana de la relatividad. Mientras, los textos y las ideas siguen desarrollándose en el contexto académico e investigativo, como resultado de un trabajo previo a esta interrupción de lo cotidiano, que hoy no está lejos de lo que puede ser una historia de ficción o de fantasía. Es que lo cotidiano lo pensábamos como sinónimo de lo rutinario, como aquello que sucede todos los días, que se reitera o que se repite a modo estructural. Sin embargo hoy, me parece que lo cotidiano por el contrario era más un momento lleno de distinciones, de acontecimientos y situaciones que construían variabilidad, en modo iterativo, sí, pero con matices, que finalmente daban vida a la vida. Me atrevo a afirmar que aún cuando, mirando la naturaleza, vemos que las estructuras se repiten, en ellas existe variabilidad, como la acción necesaria para una convivencia sana, o como la forma de evitar que nos demos vuelta tal un torbellino que lleva todo al vórtice, aunque este se desplace.

En este escenario complejo para muchos, la lectura, la investigación, las ideas, la ciencia y las artes, siguen siendo el motor de esperanza de la humanidad, pues miran el pasado y las circunstancias que permiten aclarar o descifrar la incógnita del presente; muchos en su dimensión además nos transportan a contextos distintos con el ánimo de continuar en aquello que denominábamos como cotidianidad; escribir y leer sigue siendo una actividad de gozo, y fundamentalmente prometedora. Como tal, la investigación artística prosigue su actividad a lo largo del orbe y con fuerza, como una práctica que fortalece la idea de que la investigación no es sólo aquella que imaginamos en un laboratorio, propio de la biología, de la medicina o de la química, también y siempre como un modo de mirar lo que acontece, libre y creativamente, de mirar nuestro entorno a través de indagaciones que apelan además a las emociones y los afectos.

Lo circunstancial ha agregado contradicciones a la rutina, afectando prácticas y también a las personas, transformando principalmente los haceres de lo que hoy con más fuerza se cuestiona conceptualmente, la normalidad; así podemos preguntarnos que reconocemos en lo cotidiano, cuando muchas acciones y actividades ganaron, mientras otras tantas por cierto perdieron, propio de la contradicción y cuestionamiento humano, que se vuelve precisamente más normal de lo que era; nos vamos dando cuenta que mucho de aquello que creemos conocer en rigor no podemos ni explicarlo.

La investigación tiene ese norte; explicar con cierta certeza lo fenomenológico, también cuestionarse al respecto, analizar las contradicciones, para argumentar al respecto. Hemos visto, no hace tanto, que la tecnología se cuestionase por la contradicción latente de - por una parte- sumergirnos en la individualidad mientras su discurso promocionaba -además de su desarrollo en la técnica- la anulación de las distancias, sin embargo, en gran medida se ha transformado en una aliada, como el motor de resistencia que revela la capacidad de adaptación del ser social, en razón de los contextos, asimismo de los conceptos.

La Investigación artística en particular mantiene el norte, navegando con ojo humanista y reflexivo a través de la inmensidad de nuestra existencia, desbordando los límites que la academia y lo cotidiano nos fijan, e indagando cual explorador que, mientras circunda lo que aparece, encuentra lo inesperado. Mientras muchos siguen buscando la separación entre técnica y teoría, la investigación artística se encarga de desfragmentar la realidad, con el fin de que los diálogos acerquen (o no desvinculen por defecto) la reflexión y la práctica. 
En el número actual encontramos nuevamente a la persona en el centro de la reflexión, sin desvincularse de la dimensión del ejercicio práctico, que podríamos decir es un acto más bien cotidiano, con esfuerzos que dedican tiempos diversos y que superan la mera circunstancialidad, situando la realidad de los fenómenos analizados desde la experiencia del ser social antes que en el individuo. Si bien la imagen sigue siendo el numen para los autores que colaboran con nuestra revista, aparece ahora con gran volumen, la dimensión sonora y la musicalidad en los análisis, reforzando el valor de la conexión inherente entre teoría y praxis, propia del mundo de las artes.
Alma Barbosa por su parte, reflexiona sobre el aporte de José Vasconcelos a la política artística gubernamental mexicana, desde la década de los años veinte a la actualidad, quien contribuyó a la estructuración y fortalecimiento del campo artístico, a través del mecenazgo estatal. A continuación, los textos de Federico Rodríguez, aproximan la posibilidad de pensar la práctica de la improvisación musical a través de una ecología del sujeto. Posteriormente, vemos que Patricia Castañeda y Ana María Salamé, analizan el proceso de composición de la dupla Lennon/McCartney, como legado de una amistad que desplegó una fuerza creativa colaborativa y altamente intuitiva, que contribuye en la conformación de los actuales contextos culturales contemporáneos.

Luego, un tema para nosotros siempre de mucho interés, es abordado por Francisca García e Ignacio Nieto, sobre el aparato conceptual internacional asociado a la "investigación artística", en diálogo con aproximaciones locales de investigadores chilenos; su trabajo incluye tres "insertos artísticos" que permitirán al lector acercarse a diferentes metodologías de trabajo desde una lógica teórico-práctica.

Es importante destacar que el análisis constante de la obra artística, permite ver que los temas que parecen contingentes, se enfrentan en la esfera social con antelación a lo aparente. Así, Atilio Rubino aborda el problema de la representación de la disidencia sexual en los años setenta, a partir de una película de Rainer Werner Fassbinder, permitiéndonos ver cómo los debates que marcarían la emergencia de los movimientos queer de los noventa ya estaban presentes desde esa década. Continúa nuestro número actual, con un trabajo de Fabián Villalobos, en el que se propone repensar el vínculo de la música y el sonido con la noción de identidad, para profundizar esta relación en razón de lo social y lo político.

Finalmente Martin Kanek, Jeannette Plaza y Catalina Campuzano plantean que Habitar la imagen comprende la relación mediada por lo visual entre lo interno y externo del ser, un acto que implica un movimiento en el espacio y a través del tiempo.

Como colofón del proceso editorial, pero inicio de la publicación es para nosotros un honor que el Colectivo LASTESIS se haga parte de nuestra revista, exponiendo su trabajo en el inciso. Su obra, que manifiesta más que palabras y acciones, es un reflejo de la búsqueda por la igualdad y por avanzar a una sociedad más justa, dando al feminismo el espacio que la historia le ha quitado, pero que se hace presente hoy detrás de un trabajo considerado como de lo más influyente de los últimos años y consignado el 2020. 